\title{
Painless groin mass and multiple erythematous to violaceous skin lesions
}

\author{
Cristina Méndez Díaz • Rafaela Soler Fernández • \\ Esther Rodríguez García • Carmen Delgado Sotorrío
}

Received: 23 September 2011 /Revised: 27 November 2011 / Accepted: 15 December 2011 /Published online: 11 January 2012

(C) ISS 2012

\section{History}

A 38-year-old man presented with a 2-month history of painless left groin mass and multiple erythematous to violaceous nodules and plaques on both groins and thighs. The skin lesions had gradually increased in size and number. Past medical history was unremarkable. Physical examination showed a soft and non-tender mass in the left groin and multiple bean-sized erythematous nodules and plaques on both groins and thighs. There were neither any other systemic symptoms nor lymphadenopathy. Laboratory tests were normal.

Pelvic magnetic resonance imaging (MRI) (Fig. 1) and computed tomography (CT) of the chest and abdomen were performed. Histopathology was also examined (Fig. 2). Neither abnormal lymphadenopathy nor visceral involvement was noted on chest and abdominal CT scan. What is the diagnosis?

The diagnosis can be found at doi: 10.1007/s00256-011-1352-7.

C. Méndez Díaz $\cdot$ R. Soler Fernández $\cdot$ E. Rodríguez García $(\bowtie)$

Department of Radiology, Complejo Hospitalario Universitario

A Coruña (CHUAC),

Xubias de Arriba 84,

15006 A Coruña, Spain

e-mail: esther.rodriguez@mundo-r.com

C. Delgado Sotorrío

Department of Pathology,

Complejo Hospitalario Universitario A Coruña (CHUAC),

Xubias de Arriba 84,

15006 A Coruña, Spain 

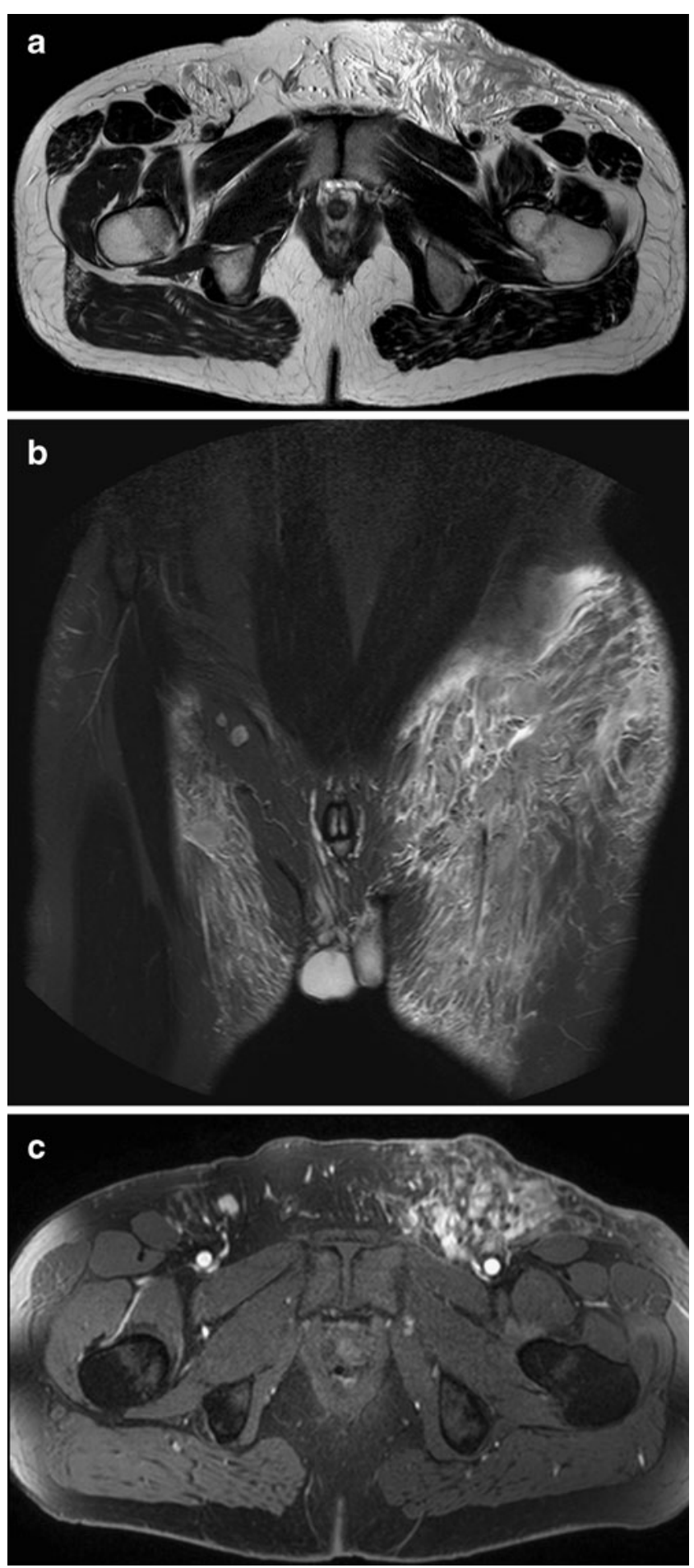

Fig. 1 Pelvic MRI (including a axial TSE-T2 weighted, b coronal T2weighted with fat saturation, and $\mathbf{c}$ axial fat-suppressed T1-weighted images after gadolinium administration) was followed by left groin subcutaneous tissue and skin core biopsy
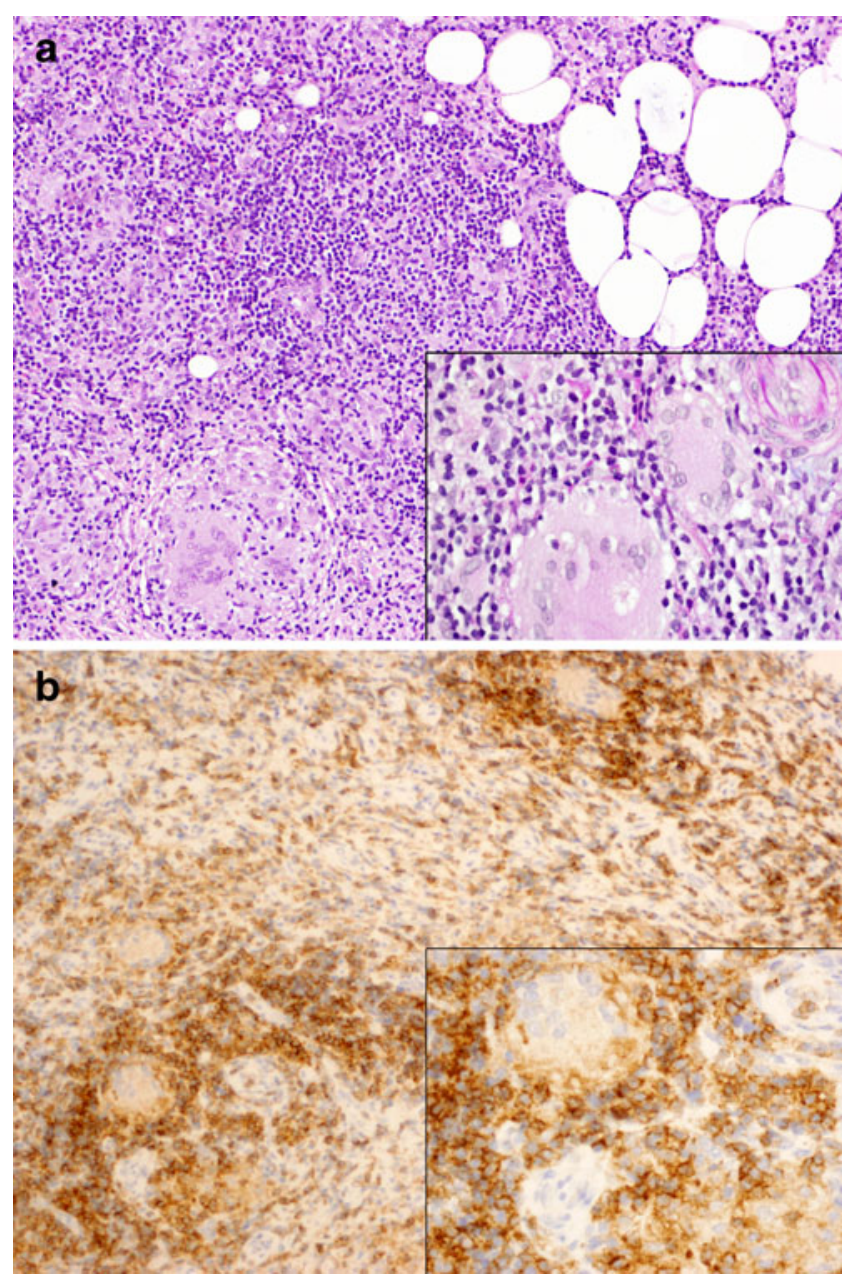

Fig. 2 a Hematoxylin and eosin stain $10 \times$ and $40 \times$, and b CD4 stain $10 \times$ and $40 \times$ 